\title{
TESTING THE QUALITY OF PISTON CASTINGS ON THE MACHINING LINE
}

\author{
${ }^{1}$ Adam KRĘPA, 2Jarosław PIĄTKOWSKI \\ ${ }^{1}$ Federal-Mogul Gorzyce, Gorzyce, Poland, EU, adam.krepa@tenneco.com \\ ${ }^{2}$ Silesian University of Technology, Gliwice, Poland, jaroslaw.piatkowski@polsl.pl
}

https://doi.org/10.37904/metal.2021.4243

\begin{abstract}
The quality control of most castings concerns finished products and is carried out at special stands after the end of the production process. However, more and more foundries decide to use the so-called inter-operational quality control, the advantage of which is the earlier detection of defective products, which allows, among others to reduce production costs. This applies in particular to the automotive sector, whose products and services require special verification in terms of quality and functionality. The article presents a method of quality control of piston castings for combustion engines with the use of the US2D ultrasound scanner. It is a nondestructive testing (NDT) device that controls $100 \%$ of all products on a given manufacturing line. This allows the detection of many imperfections in the casting, e.g. porosity, cracks, location of the cooling channel in relation to the piston crown. Thanks to this, it is possible to quickly adjust the parameters of the casting process and prevent defective products from being shipped to the customer.
\end{abstract}

Key words: Aluminum alloys, castings of pistons for internal combustion engines, quality, automotive

\section{INTRODUCTION}

Due to the dynamics of economic changes, the quality of products and services has become an important criterion influencing the success of every enterprise. Continuous quality improvement can be achieved by directing efforts towards planning and preventing problems arising at the source. The concept of quality management understood in this way is called quality assurance [1], in which the main emphasis is placed on modern quality planning, product, process, or service improvement, their control, and the involvement of all personnel [2-4].

The interdisciplinary nature of quality, changes in its understanding, and the multitude of factors influencing quality made it decide, since 1986, to consider quality in the form of standards and legal regulations. In this way, first, the ISO 9000 series standards were created, then ISO 9001 and ISO / TS, which continuously reflect the construction of line management systems in enterprises [5]. Currently, all products delivered directly to car manufacturers comply with IATF 16949: 2016 standards.

This applies especially to the automotive sector, where the so-called "Core quality tools", which include, among others process control at each section (Control Process CP) using various methods or tools [6,7]. New, stringent guidelines for reducing $\mathrm{CO}_{2}$ emissions have forced the need to design modern combustion engines, and thus the use of technologically advanced engine components. One of such parts is the piston having a special design, susceptible to any material and dimensional defects. It has therefore become imperative to detect non-compliant products at an early stage of production.

\section{PURPOSE AND SCOPE OF RESEARCH}

The aim of the study is the use of non-destructive testing, as inter-operational quality control, performed using ultrasound US2D for checking the pistons dedicated for internal combustion engines. 
The tests were carried out, among others, on the GL1 production line at the Federal-Mogul Gorzyce - Tier 1 (tier 1 suppliers work directly with OEM companies: "Original Equipment Manufacturer").

The scope of research includes:

- $\quad$ a short description of the detection capabilities of the US2D ultrasound device,

- $\quad$ identification of defects detected by US2D ultrasound and their analysis using the Pareto method.

\section{RESEARCH MATERIAL AND METHODOLOGY}

For the tests were selected piston castings for gasoline engines installed in Mercedes engines. The quality of the production process of selected piston castings was assessed by calculating the level of scraps. The US2D ultrasound scanner was used for the inter-operative evaluation of the casting quality, which was placed in the GL1 production line. The US2D device allows for the detection of defects located in the upper part of the piston casting (Figure 1).

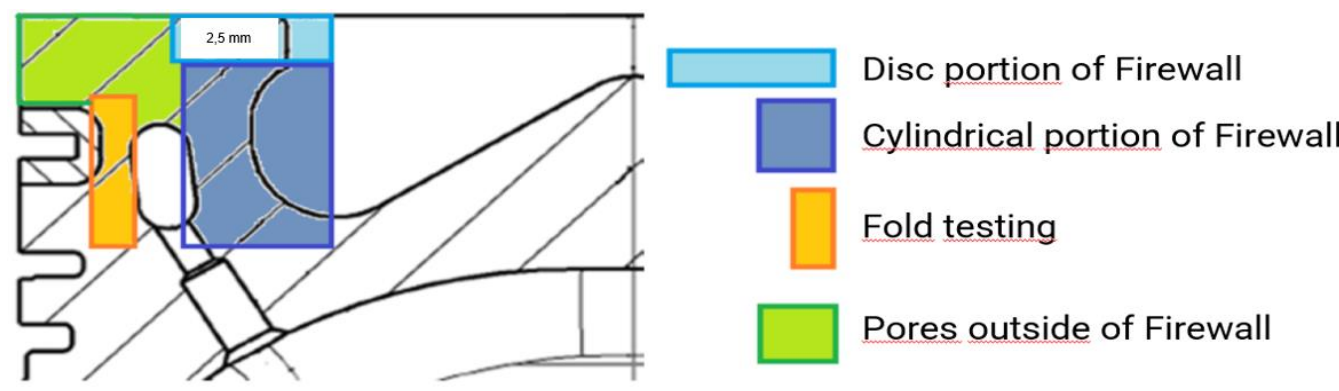

Figure 1 Schematic representation of test zones

Due to the introduction of inter-operational control with the use of the US2D device, the following defects in castings can be detected:

- folds (cracks between iron ring currier and cooling gallery),

- $\quad$ porosities outside of firewall,

- $\quad$ ring carrier - axial position,

- $\quad$ ring carrier - bonding/adhesion,

- $\quad$ porosities inside of the firewall,

- $\quad$ cooling gallery - axial position,

- $\quad$ cooling gallery - radial position and presence.

The US2D ultrasound scanner is combined with a robot that will properly prepare the piston for examination. Figure 2 shows the US2D ultrasound machine installed in-line. The quality control of castings was carried out by an appropriately set ultrasonic probe. The reflected ultrasonic signals, processed with the help of algorithms, are given in the form of $2 \mathrm{D}$ and $3 \mathrm{D}$ on the monitor of the control panel. The operating steps of the US2D ultrasound scanner are shown in Figure 3.

\section{RESULTS OF RESEARCH}

The use of in-process tests/control is aimed at:

- $\quad$ reducing the risk of sending a defective product and thus avoiding "engine scuffing" and the costs of its replacement or repair,

- $\quad$ reduction of production costs. The earlier defective products are detected, the fewer operations will be performed on an incompatible product, and therefore less cost incurred by the company,

- $\quad$ improving the efficiency of production lines. 


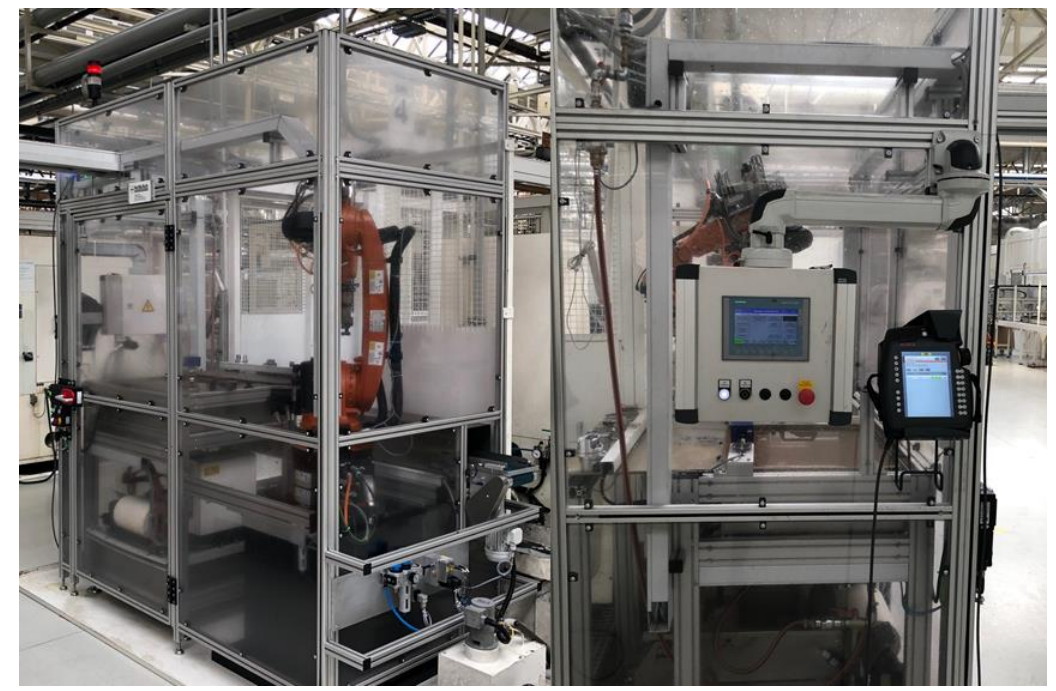

Figure 2 US2D device integrated with machining line
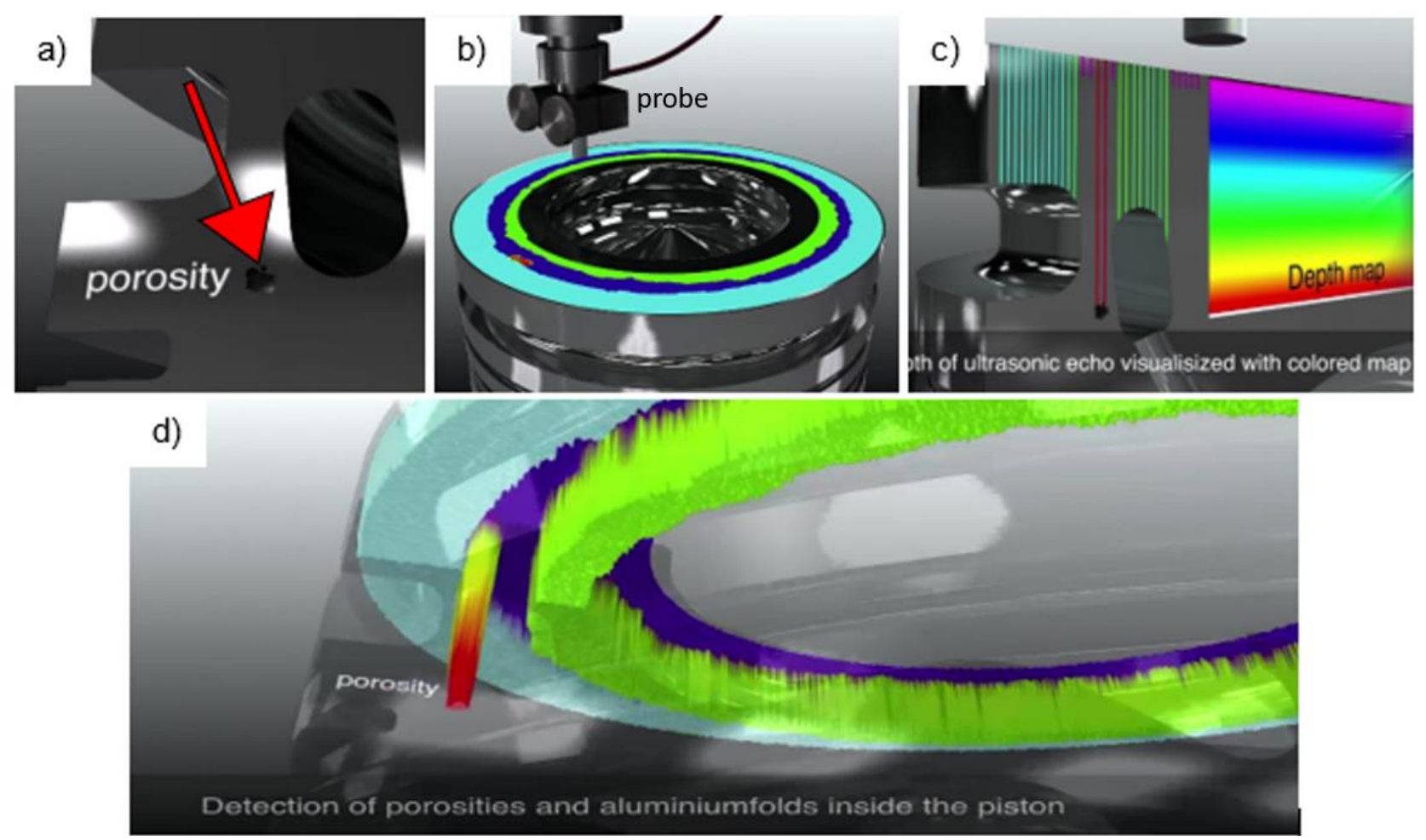

Figure 3 The operating steps of the US2D ultrasound scanner: a) defect identification, b) probe positioning, d) visualization of $2 \mathrm{D}$ ultrasonic tests, c) test results in $3 \mathrm{D}$

The use of ultrasound US2D is effective before casting the piston reaches the final size and shape. It is related to the measurement methodology and quality control requirements.

Before the US2D installation, pistons were produced that had a simple design and operated in low-efficiency engines. Thus, there was no need to use precise defect detection devices. However, the introduction of advanced products made it necessary to use ultrasound scanners. Therefore, it is not possible to compare the size of shortages before and after the use of the US2D device, but only assess the potential risk of a lack of inter-operative control of newly designed products. Figure $\mathbf{4}$ shows a Pareto chart of engine piston casting defects detected by the US2D machine over a period of three months. 


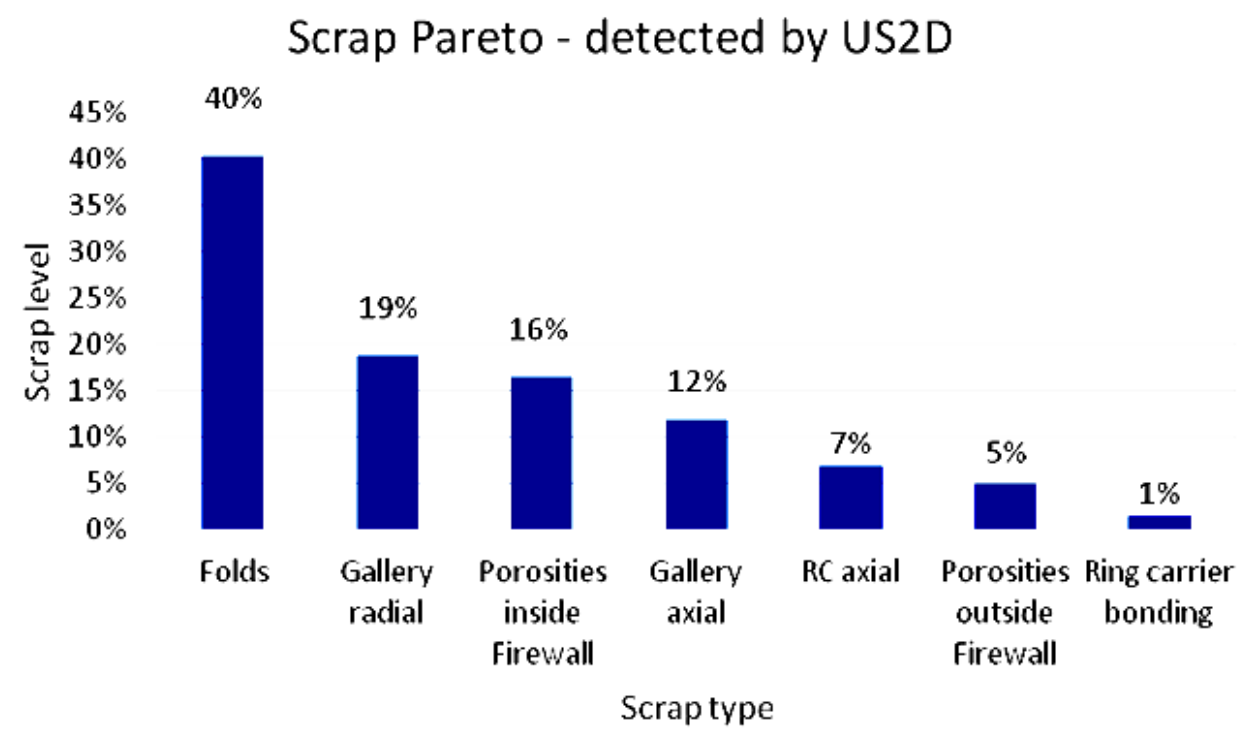

Figure 4 Scrap Pareto of piston casting defects for three months

Using the US2D ultrasound scanner and analysing product defects on the basis of the Pareto chart, we can optimize the casting process by controlling its appropriate parameters. The most common defect is a so-called fold or discontinuity between the insert and the cast iron cooling channel. Figure $\mathbf{5}$ shows the fold and image on the US2D monitor.

The analysis of defective piston castings (Figure 4) allowed to determine the causes of fold defects, which include:

- $\quad$ argon distribution before casting not correct (Figure 6a, 6b),

- $\quad$ water leak into die (Figure 6c),

- $\quad$ salt core quality (surface too smooth) (Figure 6c, 6d),

- die or salt core is too cold (Figure 6a, 6b),

- alfin or salt core setting time is too long (Figure $6 \mathbf{a}, 6 \mathbf{b}$ ).

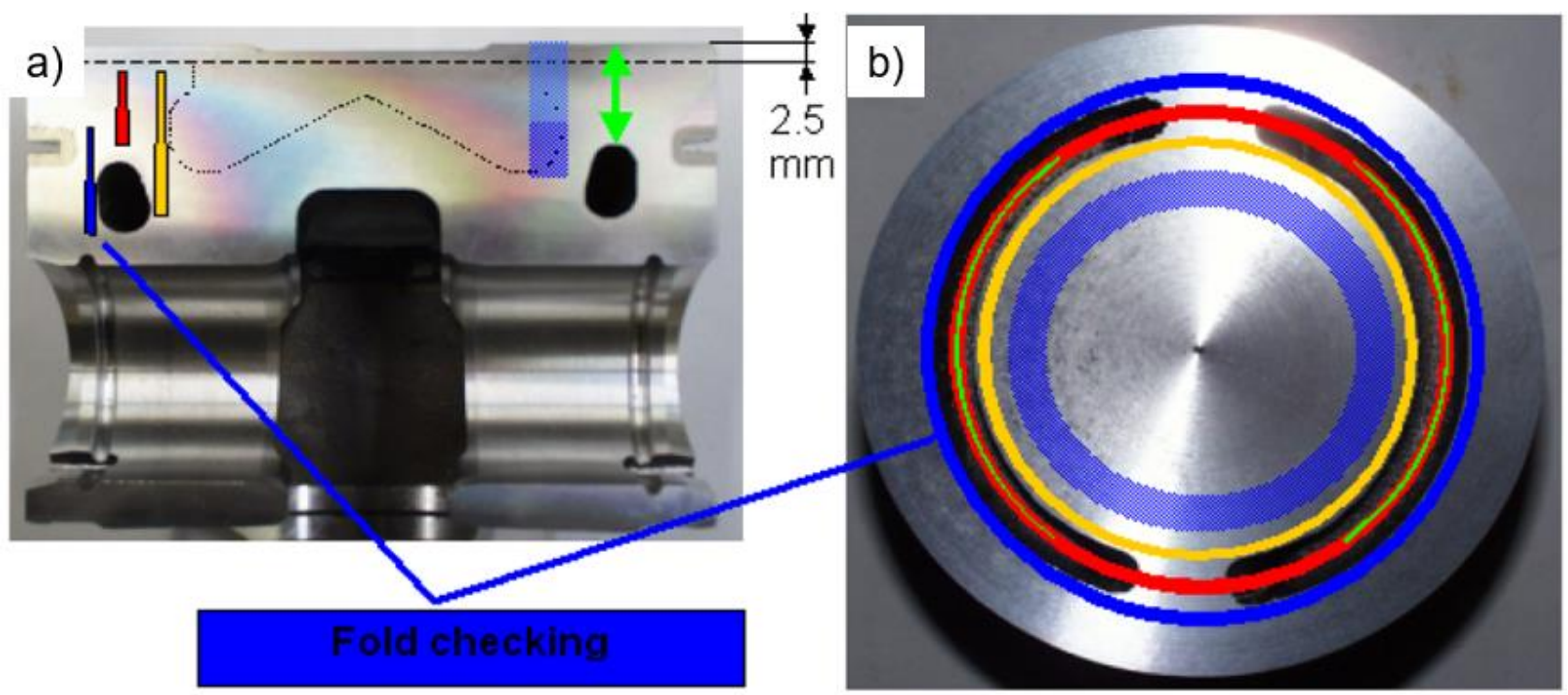

Figure 5 Folds check - by US2D: a) Sectional side view of the piston, b) top view 


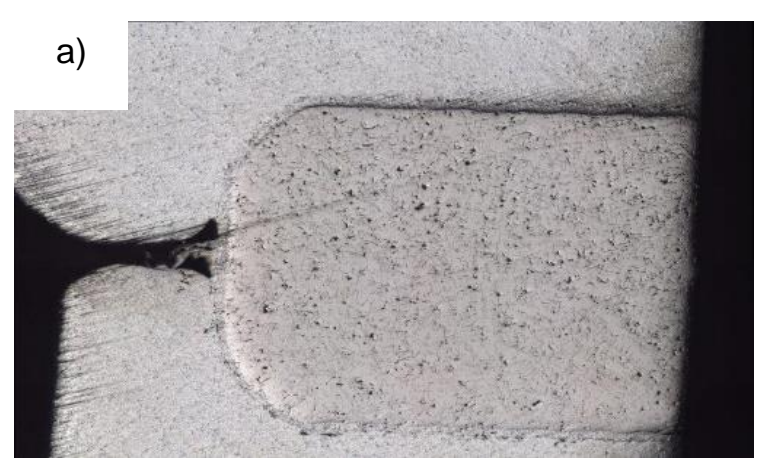

c)

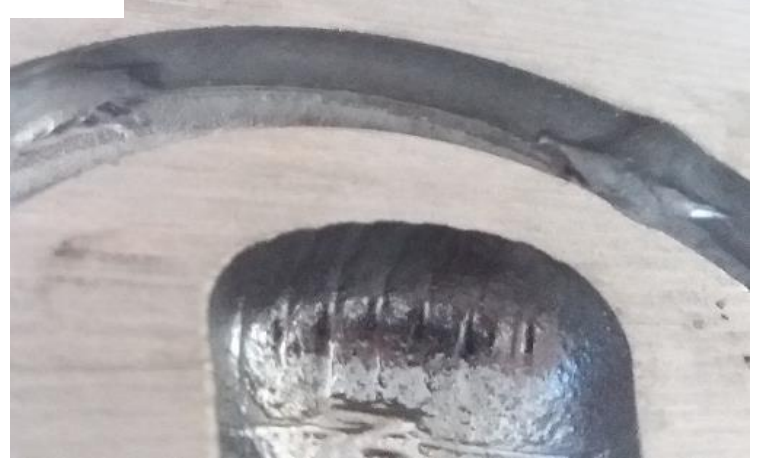

b)

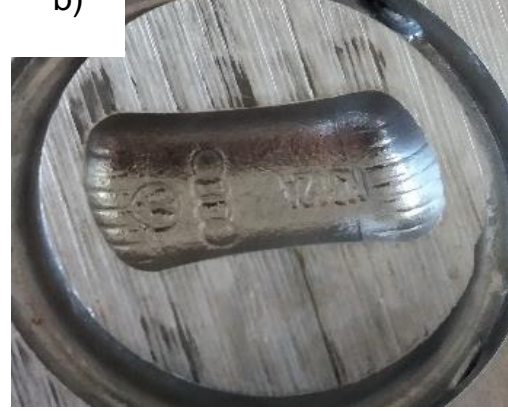

d)

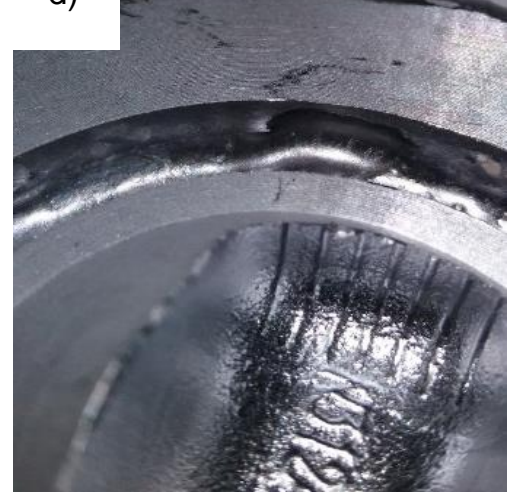

Figure 6 The causes of casting defects

Eliminating the underlying causes the formation of the most common defects (Figure 6) showed a reduction of the scraps at the end of four consecutive months (Figure 7).

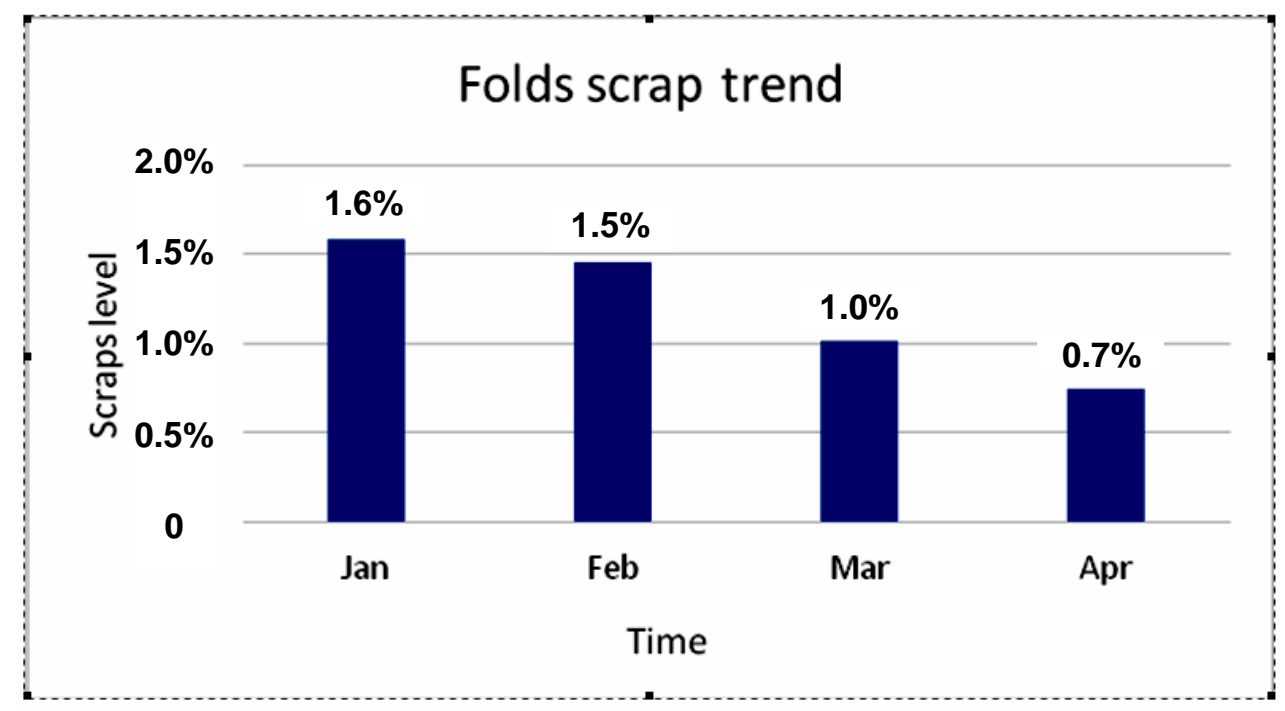

Figure 7 The scraps at the end of four consecutive months

\section{SUMMARY AND CONCLUSIONS}

New economic and ecological requirements place more and more emphasis on the development of internal combustion engines in the area of reducing fuel consumption. This applies, inter alia, to increasing ignition pressure, higher cylinder temperatures, and direct reduction of friction in engine components. In addition to the increased need for sustainability, this will continue to foster innovation in ICE technologies. 
Production plants must therefore implement new technologies that ensure better efficiency of the machine park and the quality of products and services. The products must therefore meet the highest standards and expectations of customers, and sales revenues - guarantee appropriate profits.

The US2D device installed on production lines guarantees (with 100\% product control) that the defective product cannot get into the engine and reduces production costs by "shortening the path" from the occurrence of a defect to its detection. In addition, the possibility of continuous collection and correct reporting of data during the production process, through a properly designed infrastructure, allows for a quick response to all types of inconsistencies, which guarantees continuous optimization of the process. US2D devices are an effective way to reduce the costs of complaints and production, and they are a much cheaper alternative to non-destructive testing performed with the use of an X-ray/tomograph.

On the basis of the research the following conclusions:

- The use of the US2D ultrasound machine makes sense after casting the piston and before the next stages of production. This will allow to reduce costs and effectively detect piston defects during the production process.

- Interoperative ultrasound examination of the pistons revealed about $2.8 \%$ of defects.

- The US2D ultrasound scanner significantly reduces the risk of installing defective pistons in modern car engines and eliminates the risk of high costs of potential customer complaints.

\section{BIBLIOGRAPHY}

[1] HAMROL, A. Quality management with examples. Warsaw: WN PWN, 2007.

[2] HAMROL, A., MANTURA, W. Quality management. Theory and practice. Warsaw: WN PWN, 2006.

[3] HERNAS, A., GAJDA, L. Quality management systems. Gliwice: Wydawnictwo Politechniki Śląskiej, 2011.

[4] DAHLGAARD, J.J., KRISTENSEN, K., KANJI, G.K. Fundamentals of quality management. Warsaw: PWN, 2002.

[5] WAWAK, S. Quality management. Basics, systems and tools. Gliwice: Helion, 2011.

[6] OAKLAND, J.S. Statistical Process Control. Fifth Edition. Butterworth-Heinemann, 2003.

[7] SKORMIN, V.A. Introduction to Process Control. Springer-Verlag GmBH, 2016. 